\title{
Productivity Dispersion and its Determinants: The Role of Import Penetration
}

\author{
Daniela Maggioni
}

Received: 9 February 2012 / Revised: 4 October 2012 /

Accepted: 8 October 2012 / Published online: 2 November 2012

(C) Springer Science+Business Media New York 2012

\begin{abstract}
The new heterogeneous firm models in international economics predict a negative impact of trade openness on within-sector productivity disparities, due to a restructuring process leading to a reallocation of resources towards more efficient firms and the exit of less productive ones. I test this hypothesis for the Italian manufacturing sectors making use of panel data models. I investigate the existence of heterogeneous effects in terms of origin of imports and I account for a geographical dimension computing the productivity dispersion indicator by sector and regional macro-area. The analysis is implemented within a comprehensive framework controlling for other potential determinants, such as technological factors and domestic competition. My findings show that competitive pressure from low income countries reduces the productivity heterogeneity across firms. On the contrary, a positive impact is detected for the increased availability of intermediates originating from developed countries.
\end{abstract}

Keywords productivity $\cdot$ dispersion $\cdot$ imports $\cdot$ firm heterogeneity

JEL Classification $\mathrm{L} 25 \cdot \mathrm{F} 14 \cdot \mathrm{O} 33 \cdot \mathrm{O} 47$

\section{Introduction}

Recent firm and plant-level studies have found large and persistent differences in productivity levels across firms even within narrowly defined sectors (Bartelsman and Doms 2000; Haller 2008; Escribano and Stucchi 2008). The growing availability of micro level datasets has allowed to investigate the factors affecting sectoral productivity dispersion; however, to date the scant empirical evidence is not conclusive.

D. Maggioni $(\bowtie)$

Department of Economics, Università Politecnica delle Marche,

Piazzale Martelli 8, 60121 Ancona, Italy

e-mail: d.maggioni@univpm.it 
A new strand of literature in international economics builds on firm heterogeneity (Melitz 2003; Bernard et al. 2003) and points at the role of trade liberalization as an important driver behind within-industry firm dynamics and productivity dispersion.

In this paper I first provide new evidence for Italy on the existence of a large within-sector disparity in firm productivity and, secondly, I try to shed some light on its determinants with a special focus on the role of import penetration. I test whether the predictions of the new heterogeneous firm models in international trade are supported by the data. The period of my analysis, 1998-2004, is interesting in this perspective because Italy has experienced, in most sectors, an increase of its imports, especially from less developed countries due to both the EU-enlargement and the increasing involvement of the latter in international markets. My working hypothesis is that a restructuring process has been at work in the Italian manufacturing sector following the growing inflows of foreign goods. International trade changes the context where firms operate, gives them the possibility to access foreign inputs, increases competitive pressure and opens up new business opportunities. Hence, international openness may shape sectoral dynamics. The existing evidence for Italy on this topic is limited to the paper of Del Gatto et al. (2008) showing a reduction of productivity dispersion caused by trade openness. Within this framework my main contribution is to examine, for the first time, the existence of heterogeneous effects of imports according to the origin country. Also, as opposed to Del Gatto et al. (2008), I implement a comprehensive investigation of dispersion determinants and, in addition to import penetration, I shed some light on other explanatory factors capturing the technological level of sectors and the domestic competitive context. Finally, I account for the spatial dimension computing sectoral dispersion indicators by geographical area. Local conditions matter for the competition process, firms dynamics and growth (Ottaviano and Puga 1998) and the spatial perspective may help to understand the drivers behind the within-sector differences in firm productivity. This point may be relevant for Italy, which is characterised by deep differences in the business and economic environment among regions, especially between the Centre-North and the South of the country.

My results confirm that imports in the sector and area shape the sectoral distribution of productivity although different effects are found according to the origin country. In particular, exposure to low income countries decreases the heterogeneity in productivity in a sector while imports from developed countries display a positive effect. I provide some explanations for this opposite impact of import flows from the two groups of countries on productivity dispersion.

The analysis rests on a sample constituted mostly of medium and large firms neglecting the population of micro and very small firms. The sample composition may thus affect the results and, for example, the import competition effect may be underestimated since it is likely that the competitive pressure from foreign countries has larger detrimental effects on small firms often at the lower tail of productivity distribution. Hence, caution should be paid in generalizing the conclusions of the paper to firms of all sizes.

The paper is organized as follows. The next section reviews the related literature. Section 3 describes the data and shows some descriptive statistics. Section 4 investigates the determinants of sectoral dispersion and proves the robustness of my findings. Section 5 investigates the channels behind the effects found for import penetration and trade openness. Section 6 concludes. 


\section{Review of the related literature}

The analysis of firm heterogeneity is a relatively recent research field: theoretical studies rejecting the representative firm hypothesis date back to the end of 1970s (Jovanovic 1982), and the first empirical papers followed in the 1990s (Kremp and Mairesse 1991; Oulton 1998). Investigating the reasons for the existence of large within-sector disparities can provide interesting insights about the productivity growth process. Even if research is increasing, the topic is still puzzling and the evidence is scant.

Productivity heterogeneity can be explained by both supply-side factors and demand-side determinants. The latter set of explanatory variables has been investigated in Syverson (2004). The author exploits the 1977 US Census of Manufactures and shows a negative correlation between product substitutability, that generates stronger competition, and the disparity of producer productivity levels. Also, he finds that sectors more exposed to international trade present higher productivity dispersion. In line with Syverson (2004), Ito and Lechevalier (2009) provide evidence on the role of internationalisation on dispersion for Japan. They find a positive impact of both export intensity and import penetration on sectoral productivity dispersion. In contrast to this empirical evidence, according to the new international trade literature based on firm heterogeneity (Melitz 2003; Bernard et al. 2003 ${ }^{1}$ ) trade openness should cause a resource reallocation toward more efficient firms, the exit of less productive firms and the entry of more productive ones, and, as a consequence, a lower within-sector dispersion should be observed. These theoretical predictions are supported by Del Gatto et al. (2008) that, contrary to previous empirical analyses, find a negative impact of trade openness on within-sector dispersion in Italy over the period 1983-1999. Thus, the existing mixed findings call for additional evidence.

Even if the paper focuses on productivity dispersion, the wide literature studying the impact of trade openness on firm and sector productivity levels represents an important starting point. Many theoretical and empirical contributions support the positive effects of international integration and both the channels of easier access to foreign market and higher competition have been investigated (Pavcnik 2002; Amiti and Konings 2007; Fernandes 2007; Khandelwal and Topalova 2011). Focusing on Italy, Bugamelli and Rosolia (2006) find that competition from non developed countries has positively affected the productivity of sectors, while, at firm level, Altomonte et al. (2008) disclose efficiency gains stemming from both horizontal and vertical-from upstream and downstream sectors-import flows. However, the beneficial impact of trade is challenged by some models highlighting the possibility that trade liberalization and import competition reduce a firm's investments in efficiency improvements due to the potential loss of markets shares (Rodrik 1991).

\footnotetext{
${ }^{1}$ Melitz (2003) and Bernard et al. (2003) highlight two different mechanisms for the same outcomes. In Melitz (2003), falling trade costs increase the profits for exporters, and the growing factor demand by the latter and by new entrants, caused by the expectation of higher profits, pushes upward the real factor prices, and this drives the least productive firms out of the market. In Bernard et al. (2003), low productivity plants exit the market because of the growing competitive pressure from foreign firms.
} 
Recent empirical contributions investigate the potential asymmetrical impact of sectoral factors and external shocks on firm productivity and provide a bridge between the two reviewed streams of literature: the one dealing with the analysis of the sectoral dispersion and the one focusing on the determinants of the average productivity level. Globalisation, R\&D, FDI spillovers and competition turn out to asymmetrically affect the efficiency of the firm according to its initial position in the productivity distribution (Griffith et al. 2003; Sabirianova et al. 2005; Bekes et al. 2009). Schor (2004) and Dimova (2008) show that trade liberalization in Brazil and Bulgaria, and the resulting increased competition, led firms at the lower tail of productivity distribution to increase their efficiency in order to survive in the market. The same is not true for highly productive firms that do not face a high failure risk (Muendler 2004). However, different conclusions are presented in Iacovone (2009) that, in line with the predictions of neo-Schumpeterian growth theories (Aghion et al. 2005), shows weaker positive effects on productivity following the liberalization in Mexico for plants more distant to the technology frontier. Only firms close to the productive frontier increase their innovative efforts in order to prevent entry of potential foreign competitors, on the contrary less efficient firms are not able to successfully compete with foreign entrants at the frontier.

Thus, if international trade flows, technological factors or other external shocks have heterogeneous effects on firm productivity, some significant consequences may emerge for the within-sector dispersion. In particular, even if import flows have been investigated as a determinant of the productivity dispersion, two different channels could lie behind this relationship. Previous evidence has mainly focused on the tougher competition driven by inflows of foreign goods. However, international integration also offers to domestic firms the opportunity to exploit an increased variety of intermediates that may be cheaper and/or characterised by higher quality and technological content than domestic ones. Halpern et al. (2005) and Kasahara and Rodrigue (2008) have highlighted the positive role of imported inputs on firm efficiency levels, but the role on productivity dispersion has been neglected. When analysing aggregated data on import flows it is relevant to distinguish the role of foreign competitive pressure and the effect related to firms' offshoring strategies.

\section{Sample construction and descriptive statistics}

\subsection{Data}

For the empirical analysis I make use of the commercial database AIDA, the online version, produced by the private company Bureau Van Dijk. This database contains unconsolidated balance sheet information on Italian firms and I recover data for manufacturing firms over the period 1998-2004. Bureau van Dijk updates regularly the dataset: firms that exit or stop reporting their financial statements for four years are kept in the sample, but after the fifth year of non-reporting they are removed. Additionally, through the sample period, the criteria for firm inclusion have been changed. All firms with a turnover higher than a fixed threshold are recorded but this threshold lowered over time: in 1998 and till 2000 firms included in the database were the ones with a turnover higher than 1 million euros, in 2002 the threshold was set to 500,000 euros and in 2004 to 100,000 euros. Taking into account these database 
characteristics I have retrieved data for deleted firms - the potentially exited firmsexploiting the different releases of AIDA CD-ROMs concerning the years of my sample. ${ }^{2}$ I have, then, dropped firms having a turnover lower than 1 million of euros, the 1998 threshold, in order to focus on a uniform sample. As a consequence, data tend to be more representative of larger firms, however medium and small firms also enter my sample as confirmed in Table 5 in the Appendix showing the firm distribution across size classes. I exploit the information about region and firm sector of activity at 2-digit NACE level. The former information allows me to define three Italian geographical areas where the firm may operate: North, Centre and South. ${ }^{3}$ I use the value of operating revenues as a proxy for output, the value of firm level tangible fixed assets as a proxy for fixed capital, and the number of employees ${ }^{4}$ and materials and services costs as proxies for inputs. I deflate nominal variables using sectoral price indexes for output, value added, materials and capital stock. Observations with missing values for the variables of interest (output, inputs), or with implausible figures (for example, negative values), or which present some gaps over the sample period are dropped. After this cleaning procedure I have information about more than 30,000 firms over the sample period.

The measure of firm efficiency used in the analysis is the firm multilateral index of Total Factor Productivity, TFP, suggested by Caves et al. (1982). I have computed the index separately for each 2-digit sector and area resting on a value-added specification of the production function. Table 6 of the Appendix displays the cost shares I used by sector, averaged across areas. ${ }^{5}$ Making use of these productivity estimates I obtain the following dispersion indicators at 2-digit NACE sector disaggregation and for each area: ${ }^{6}$ the interquartile range of the log of productivity, D2575,

\footnotetext{
${ }^{2}$ The inclusion of exited firms is essential for my analysis because the explanatory variables, especially import penetration, could affect the within-sector productivity dynamics through the firm exit process.

${ }^{3}$ The three areas are defined as follows. North includes the regions of Valle d'Aosta, Piemonte, Liguria, Lombardia, Trentino Alto Adige, Friuli Venezia Giulia, Veneto, Emilia Romagna. Centre includes the regions of Toscana, Marche, Lazio, Umbria. South includes the regions of Campania, Abruzzo, Basilicata, Molise, Puglia, Calabria, Sicilia, Sardegna.

${ }^{4}$ The number of employees is missing in some cases because firms have no duty to declare this information to the Chambers of Commerce. On the contrary the information about the personnel costs is always present. In order to keep the largest sample as possible I have replaced missing data for the number of employees with the product between the firm personnel cost of each year and the average unit labour cost of the firm in the previous year, in the belief that the unit labour cost is quite constant in the short-term for the firm. The correlation between labour costs and number of employees is significant and higher than $92 \%$. The share of imputed labour data is less than $10 \%$ of the whole sample.

${ }^{5}$ More details about the TFP index computation are available from the author upon request. Van Biesebroeck (2007) shows that, apart the case of large measurement errors in the data, the index is robust and produces consistently accurate productivity growth estimates, even when firms are likely to employ different technologies.

${ }^{6} \mathrm{~A}$ higher disaggregation of data, at 3 or 4 digit sectoral level and at regional level, would be preferable, however with the data at my disposal this approach would lead to the computation of dispersion indicators exploiting very few observations, and most of the explanatory variables would be in any case computed at an aggregated level due to the lack of disaggregated data. There is a trade-off between having the most detailed picture and resting on reliable data.
} 
that is my favourite indicator, and, as robustness check, the standard deviation of the $\log$ of productivity, STD (as in Oulton 1998). ${ }^{7}$ Additionally, Labour Productivity, $L P$, defined as value added per employee, has been used as an alternative indicator of firm efficiency. In the latter case, the dispersion measure is standardised by the area-sectoral median value of productivity to account for the scale differences across sectors (see Syverson 2004). The distribution of firms across sectors and geographical areas in the sample of the analysis is displayed in Table 7 of the Appendix.

The North/Centre/South geographical breakdown, that is usually adopted in the literature dealing with the differences in Italian regional development patterns, allows to take into account the importance of the local context for the competition process, firms dynamics and growth. The relevance of the geographical dimension for the analysis of dispersion is confirmed in Table 8 of the Appendix. The table shows that the variation of the dispersion indicators is important both across sectors and across areas. Indeed, the three areas may present significantly different levels of productivity dispersion within the same manufacturing sector. However, in a robustness check I will relax the hypothesis of different evolution and determinants of productivity dispersion according to the geographical area and I will focus on the sectoral dimension only.

Concerning the explanatory factors tested in the analysis, the import penetration ratio, that is the main focus of the paper, is built as:

$$
I M P_{\mathrm{jat}}=\frac{M_{\mathrm{jat}}}{M_{\mathrm{jat}}+Y_{\mathrm{jat}}-X_{\mathrm{jat}}}
$$

where $j$ indexes a 2-digit sector and $a$ denotes each of the three Italian regional areas (North, Centre and South), $M_{\text {jat }}$ and $X_{\text {jat }}$ are, respectively, the total imports and exports of the area $a$ and sector $j$ in the year $t$, and $Y_{\text {jat }}$ is the total sector-area output. Also, import penetration ratio have been split according to the development level of the partner country. I used the classification between high, medium and low income countries from the World Bank, and I obtained the import penetration from low and medium income countries, $I M P_{\text {jat }}^{\mathrm{LMC}}$, and from high income countries, $I M P_{\text {jat }}^{\mathrm{HC}}$. Trade data are from the COE database by ISTAT containing information on the international flows of goods for each Italian province and destination/origin country, while sector-area output data are from the ISTAT Firm Economic Accounts. The same datasets allow me to obtain export openness ratios at sector and area level, $E X P_{\text {jat }}$, as the share of export flows over the total output.

Making use of the AIDA database I have, then, computed the concentration ratios, $C 10$ (the sectoral output share of the ten firms with the greatest market share), the sunk entry costs measured by the average amount of firm capital intensity in the

\footnotetext{
${ }^{7}$ I have also tried to use the interdecile range (D1090), but this indicator may be severely affected by the presence of outliers. Indeed, I found some changes in the significance of the explanatory variables between the TFP index and the TFP measure calculated following the Levinshon and Petrin (2003) approach, which will be used to prove the robustness of the findings, even if the coefficient signs do not change. Hence, I have preferred to focus on interquartile range and standard deviation giving consistent results across the different TFP estimates.
} 
sector/area, $K L$, and the average debt share on total assets across industries and areas, $L E V$. The former indicator is used as a proxy for the sectoral degree of domestic competition. Finally, I test for the ratio between the sectoral R\&D expenses over the total sectoral production retrieved from the National Input Output (IO) Tables, $R D .{ }^{8}$

I am aware that the under-representation of small firms could prevent me to investigate an important part of the story. This is a common drawback of many firm level analyses related to the lack of reliable economic information about small firms. However, I am trustful that the bias in the results is not so severe: I find that the median firm size, in terms of number of employees, is 29 employees. See Table 5 in Appendix. Also, in Table 9 I show the distribution of manufacturing output across 2digit NACE sectors for the universe and the analysed sample. The two distributions are very similar and, at this point of view, the sample may be considered representative of the population. Therefore, the reader should keep in mind the main focus of the present paper on large and medium firms.

Because of my interest in within-sector dynamics I require a firms' sample enough large for each investigated unit (sector/area), thus I have discarded those area-sector pairs with a low number of firms by year in order to obtain reliable measures for sectoral dispersion. Additionally, the analysis does not include some sector/area/year observations for which I could not construct the respective trade indicators due to the missing values for sector-regional output, because of confidentiality reasons, in the Firm Economic Accounts. ${ }^{9}$

\subsection{Descriptive statistics}

Before moving to the econometrical analysis it is useful to investigate the trends in the variables of interest. My estimations witness the disappointing productivity growth in Italian manufacturing over the sample period. Figure 1 displays the TFP evolution, however the LP evolution, even if not shown, is similar. For the whole manufacturing sector, after some efficiency gain in 1999 the productivity fell until 2003 , followed by a slight improvement in 2004 . The poor productivity evolution characterises all industries. This evidence found at micro-level confirms the studies at sector level in Italy and reproduces the results presented by Altomonte et al. (2008). Daveri and Jona-Lasinio (2005) also argue that after a period of productivity growth since 1970s and till 1995 the Italian manufacturing sector firstly experienced a stagnant evolution of productivity and, secondly, a declining path. This worrisome

\footnotetext{
${ }^{8}$ The R\&D variable is calculated as the sectoral purchases from the sector 73 Research and Development on the total sectoral production. I construct this indicator at 2-digit NACE sector level disregarding any geographical breakdown. The use of an alternative indicator of ICT capital stock, retrieved from the ISTAT National Accounts, bears similar results.

${ }^{9}$ Dispersion indicators calculated on too much small samples are not reliable. This problem concerns only some high or medium-high tech sectors in the South of Italy: the NACE sectors 30, 32, 33 and 35 in South. Also, due to the lack of data on import penetration the following observations are excluded from the analysis: in 1999 the sectors 15, 34 and 35 in North and South; in 2001 the sectors 19 and 35 in North and South; in 2002 the sector 19 in North and South; in 2003 the sectors 15 and 19 in North and South. Firms belonging to the sector-area pairs I exclude from the analysis account for about $3.8 \%$ of the total sample output over the period 1998-2004.
} 
Fig. 1 TFP evolution

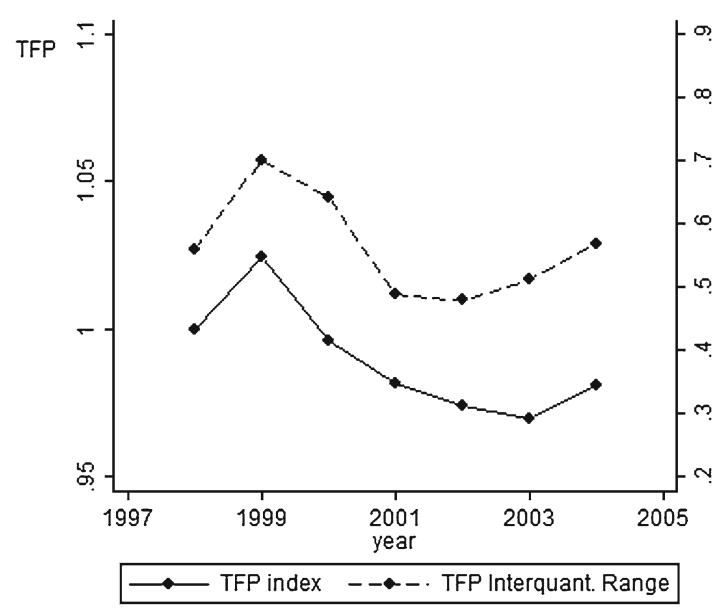

picture has drawn the attention of both economists and policy makers in Italy in the last decades. The reasons suggested to explain this trend are different: the poor institutional quality of the business environment, the low investment rates in tangible assets and innovation and the underdevelopment of capital markets together with the small size of the median Italian firm. However, no consensus has emerged in the literature. The openness to international trade may also have played an important role in shaping the productivity dynamics and I provide some evidence on this issue throughout the paper.

Focusing the attention on within-sector productivity heterogeneity, Table 1 displays the average values of dispersion by 2-digit level sector. Some differences exist across industries. The sectors characterised by the highest level of productivity heterogeneity are Manufacture of wearing apparel (NACE 18) and Office machinery and computers (NACE 30), on the contrary Manufacture of fabricated metal products (NACE 28) and Electrical machinery and apparatus (NACE 21) sectors present the lowest dispersion. The analysis of the time evolution does not show a monotonic trend in dispersion, but it is interesting to notice in Fig. 1 that during the expansion periods, when the average productivity grows, the within-sector heterogeneity increases, while disparities decrease together with a downturn in the average productivity. ${ }^{10}$ The values found for sectoral dispersion in Italy are similar to the ones presented in Syverson (2004) for USA.

Focusing on the linkages between import penetration and domestic efficiency, it is important to keep in mind that two different effects could be at work behind the inflows of foreign goods. First of all, imports lead to tougher competition in the domestic market. Secondly, the openness to foreign supply markets increases the availability of intermediates that may be cheaper or characterised by a higher quality

\footnotetext{
${ }^{10}$ This is consistent with the analysis of Escribano and Stucchi (2008) that shows lower persistence and faster convergence in TFP during recessions and higher persistence and non convergence in TFP during expansions.
} 
Table 1 Dispersion and import penetration by sector

\begin{tabular}{|c|c|c|c|c|c|c|}
\hline \multirow[b]{2}{*}{ NACE } & \multicolumn{2}{|c|}{ TFP 2004} & \multicolumn{2}{|l|}{$\% 2004$} & \multicolumn{2}{|c|}{$\Delta \%$ 1998-2004 } \\
\hline & $\overline{\mathrm{D} 2575}$ & $\overline{\text { STD }}$ & $\overline{I M P^{\mathrm{LMC}}}$ & $I M P^{\mathrm{HC}}$ & $\overline{I M P^{\mathrm{LMC}}}$ & $I M P^{\mathrm{HC}}$ \\
\hline$\overline{15}$ & 0.641 & 0.652 & 3.10 & 10.47 & 40.81 & -2.04 \\
\hline 17 & 0.620 & 0.623 & 15.42 & 10.61 & 94.03 & -22.14 \\
\hline 18 & 0.686 & 0.709 & 16.68 & 5.69 & 50.95 & -17.52 \\
\hline 19 & 0.575 & 0.593 & 25.57 & 9.30 & 68.72 & 41.66 \\
\hline 20 & 0.476 & 0.500 & 6.21 & 8.63 & -6.41 & -18.16 \\
\hline 21 & 0.427 & 0.524 & 3.50 & 19.98 & 50.60 & -9.12 \\
\hline 22 & 0.604 & 0.615 & 0.15 & 2.41 & 8.82 & 1.50 \\
\hline 24 & 0.671 & 0.668 & 4.03 & 43.40 & 20.00 & 24.85 \\
\hline 25 & 0.525 & 0.561 & 3.39 & 15.11 & 50.31 & 5.35 \\
\hline 26 & 0.529 & 0.505 & 2.29 & 5.19 & 52.38 & -30.51 \\
\hline 27 & 0.463 & 0.491 & 19.73 & 25.39 & 64.51 & -3.40 \\
\hline 28 & 0.452 & 0.499 & 1.44 & 3.37 & 100.54 & -22.33 \\
\hline 29 & 0.539 & 0.549 & 5.24 & 25.93 & 235.66 & -9.62 \\
\hline 30 & 0.827 & 0.726 & 8.92 & 76.94 & 238.47 & 26.57 \\
\hline 31 & 0.533 & 0.556 & 5.82 & 19.46 & 81.76 & 4.40 \\
\hline 32 & 0.575 & 0.664 & 12.31 & 58.17 & 257.74 & 65.04 \\
\hline 33 & 0.565 & 0.521 & 4.01 & 44.28 & 86.72 & 20.85 \\
\hline 34 & 0.584 & 0.566 & 6.75 & 54.67 & 565.91 & 36.33 \\
\hline 35 & 0.544 & 0.676 & 2.44 & 41.45 & 44.20 & 16.50 \\
\hline 36 & 0.599 & 0.626 & 7.30 & 7.36 & 36.04 & -15.53 \\
\hline
\end{tabular}

Source: own elaborations with AIDA, COE Database and Firms Economic Accounts (ISTAT). $I M P^{\mathrm{HC}}$ and $I M P^{\mathrm{LMC}}$ are Italian import penetration ratios from HCs and LMCs. All variables are calculated at 2-digit sector-area level and then averaged on 2-digit sectors

and technological content with respect to the domestic ones (Halpern et al. 2005; Kasahara and Rodrigue 2008). Hence, the same import flow may represent a threat for firms operating in that sector and an opportunity for the downstream firms. This issue is relevant for my analysis since I focus on a highly aggregated definition of sectors and the effect found out for sectoral import penetration may indeed capture both the channels. The National Input-Output (IO) tables show that the narrow input share, that is the share of both imported and domestic inputs coming from the same sector at 2-digit level over the total purchases, is not so high, but it may in any case affect my results. I find, for example, an average narrow share of $25 \%$ across manufacturing sectors and a narrow import share of $11 \%$ for the year 2004 . In order to shed light on the mechanisms at work I will try in Section 5 to dissect the effect driven by the stronger competitive pressure from the effect related to the firms' offshoring strategies by means of sectoral indicators of imported final goods and offshoring measures by origin country.

Looking at the exposure to import in Table 1, it is evident that, even if high income countries (henceforth, HCs) are still the main trade partners of Italy, the role of low and medium income countries (henceforth, LMCs) has increased over time and this phenomenon is common to all sectors. The import share from LMCs differs across industries: the largest shares are, as expected, recorded by traditional sectors, NACE 18 and 19 sectors (Manufacture of wearing apparel and Manufacture of leather and leather products), while the lowest share concerns NACE 22 sector (Publishing, printing and reproduction of recorded media). However, all sectors have experienced 
a growing competition from this group of economies. For the whole manufacturing sector the import penetration from LMCs countries increased from more than $4.7 \%$ in 1998 to $7.7 \%$ in 2004. This surge is in great part attributable to the industrial development and liberalization strategies of these countries and, according to WITSCOMTRADE data, ${ }^{11}$ it came with an increase of their total world export share. The importance of Italian imports from industrialized countries has been, on the contrary, quite constant for the total manufacturing sector over the sample period. The average increase in imports from high income countries is $4.6 \%$, but in this case there are also heterogeneous trends across sectors.

\section{The determinants of sectoral dispersion}

\subsection{The baseline findings}

In this section I analyse the factors affecting within-industry productivity differences across firms. Building on previous empirical studies I account for the following determinants: the competitive environment, the technology level and the international involvement of the sector. First, I expect that a tougher domestic competition lowers sectoral dispersion. In a more contestable market inefficient firms can not survive for a long time, firms make efforts in order to improve their efficiency and stay in the market and competitive pressures lead to the flattening of any difference. I use the concentration ratio, $\mathrm{ClO}$, at sector and area level to capture the local competitive context and I also add a variable for the sunk entry cost.

Second, I test for the role of R\&D that may have an ambiguous impact on dispersion. On one side, the adoption of new technologies is a gradual process and represents an important source of heterogeneity among firms in the same industry. As shown by Jovanovic and Lach (1997) the diffusion of technologies often takes a long time and may generate persistent within-industry efficiency disparities across firms. However, knowledge spillovers stemming from firms' innovation and R\&D activities may also play an important role, positively affecting the efficiency of all firms and favouring the catching up process of less productive ones.

Additionally, I investigate the effect of an indicator of average debt share on total assets for each sector/area pair. A high firm leverage points out the risk of bankruptcy, but also reveals the access to external financial funds, that could affect firm productivity (Nunes et al. 2007; Gatti and Love 2008) and, then, within-sector dispersion. Indeed, the lack of external financial resources could prevent firms to make investments and start new projects. As a consequence, one can expect that the availability of external resources reduces productivity differences across firms stemming from different internal financial health conditions. ${ }^{12}$ However, the effect of this variable mainly remains an empirical issue.

\footnotetext{
${ }^{11}$ The world export shares of LMCs are available upon request. Over the sample period I found an average increase rate of $53 \%$ for these shares across manufacturing sectors.

${ }^{12}$ Becchetti and Trovato (2002) have found that firms with a high leverage grow more.
} 
My main focus is on the role of sectoral international involvement. As argued in the literature review, the new heterogeneous firms trade models predict a reduction of dispersion following trade liberalisation and increased trade openness. I test for the effects of import penetration from both low-medium and high income economies resting on the idea that the flows of goods from the two country groups present different characteristics and different reasons, and a heterogeneous impact may be displayed. ${ }^{13}$

Building on this comprehensive framework, I run the following regression:

$$
\begin{aligned}
D I S P_{\mathrm{jat}}= & \alpha+\beta I M P_{\mathrm{jat}}^{\mathrm{LMC}}+\delta I M P_{\mathrm{jat}}^{\mathrm{HC}}+\phi R D_{\mathrm{jt}}+\gamma L E V_{\mathrm{jat}} \\
& +\eta D O M{ }_{c} c o m p_{\mathrm{jat}}+d_{\mathrm{ja}}+d_{t}+\epsilon_{\mathrm{jat}}
\end{aligned}
$$

where $D I S P_{\text {jat }}$ is the dispersion indicator that could be the interquartile range $\left(D 2575_{\text {jat }}\right)$ or the standard deviation $\left(S T D_{\text {jat }}\right)$ for TFP index or log of LP in each $j$-sector and $a$-area pair. $I M P_{\text {jat }}^{\mathrm{LMC}}$ and $I M P_{\text {jat }}^{\mathrm{HC}}$ are the import penetration ratios in sector $j$ and area $a$ from low and medium income countries and from high income countries, respectively; $R D_{\mathrm{jt}}$ is the R\&D share over output in the $j$ sector; $L E V_{\text {jat }}$ is the average firm debt share on total assets in the sector-area and $D O M \_c o m p_{\text {jat }}$ consists of variables capturing the domestic competitive pressure in the sector-area, that is the $C 10$ ratio and the average firm capital intensity, $K L$. All variables refer to a 2-digit NACE sector and geographical area pair with the exception of R\&D intensity that varies only by sector. The pairwise correlations among covariates are shown in the Appendix (Table 10). Every regression includes sector-area fixed effects and time dummies. ${ }^{14}$

Before estimating the model, I investigate the strict exogeneity of the regressors exploiting the test suggested by Wooldridge (2002, p. 285). Using fixed effects, this test involves regressing the dependent variable on current independent variables $X_{\text {it }}$ and on their leading values, $X_{i, t+1}$. The null hypothesis of strict exogeneity is rejected if the leading values are jointly statistically significant. I applied this test including the forward values for all regressors and an F-test can not reject the null hypothesis $(\mathrm{P}-\mathrm{Value}=0.293$ for the TFP interquartile range $)$. It follows that my right-side variables are strictly exogenous and estimates are consistent.

Table 2 shows the results for Eq. 1 estimated by Fixed Effects (FE). Imports from the two groups of countries play different roles. While exposure to less developed countries reduces within-sector heterogeneity, the opposite effect is detected for import penetration from developed countries and this evidence is confirmed for both the dispersion indicators, standard deviation and interquartile range, and for both the productivity indicators, TFP index and LP. A possible explanation for these findings

\footnotetext{
${ }^{13}$ Because of my interest on the role of competition stemming from imports, I do not include in the main analysis the export openness due to collinearity problems. In particular, export openness indicators present a high and significant correlation of more than $72 \%$ with the import penetration from developed economies. However, when controlling for the export openness in the robustness checks results do not significantly change and this variable is not significant.

${ }^{14}$ I tested different specifications for Eq. 1 confirming main results, for example replacing the R\&D intensity with an indicator of sectoral ICT capital stock or excluding some variables.
} 
Table 2 Determinants of sectoral dispersion

\begin{tabular}{|c|c|c|c|c|}
\hline & \multicolumn{2}{|l|}{$\mathrm{LP}$} & \multicolumn{2}{|l|}{ TFP } \\
\hline & D2575 & STD & D2575 & STD \\
\hline & (1) & (2) & (3) & (4) \\
\hline \multirow[t]{2}{*}{$I M P^{\mathrm{LMC}}$} & $-0.954 * * *$ & $-0.763 * * *$ & $-0.763 * * *$ & -0.910 *** \\
\hline & {$[0.270]$} & {$[0.272]$} & {$[0.220]$} & [0.298] \\
\hline \multirow[t]{2}{*}{$I M P^{\mathrm{HC}}$} & $0.285^{* * *}$ & $0.142 * * *$ & $0.163 * * *$ & 0.144 \\
\hline & [0.050] & [0.047] & [0.057] & [0.090] \\
\hline \multirow[t]{2}{*}{$K L$} & $0.054 * * *$ & $0.128 * * *$ & $0.033 * *$ & $0.091 * * *$ \\
\hline & [0.017] & {$[0.028]$} & [0.014] & [0.023] \\
\hline \multirow[t]{2}{*}{$L E V$} & $-0.842 * * *$ & -0.260 & $-0.801 * * *$ & -0.162 \\
\hline & {$[0.245]$} & [0.619] & [0.282] & {$[0.663]$} \\
\hline \multirow[t]{2}{*}{$C 10$} & -0.009 & -0.008 & -0.066 & 0.036 \\
\hline & {$[0.051]$} & {$[0.070]$} & [0.049] & {$[0.072]$} \\
\hline \multirow[t]{2}{*}{$R D$} & $-0.106 * *$ & -0.0993 & $-0.132 *$ & -0.125 \\
\hline & {$[0.052]$} & [0.077] & {$[0.075]$} & [0.081] \\
\hline \multirow[t]{2}{*}{ Const } & 0.387 & -0.262 & 0.312 & -0.363 \\
\hline & [0.285] & {$[0.741]$} & [0.410] & [0.835] \\
\hline Obs. & 378 & 378 & 378 & 378 \\
\hline$R^{2}$ & 0.646 & 0.623 & 0.592 & 0.53 \\
\hline$N$ groups & 56 & 56 & 56 & 56 \\
\hline
\end{tabular}

Robust standard errors in brackets. $* * * \mathrm{p}<0.01, * * \mathrm{p}<0.05, * \mathrm{p}<0.1$ Fixed Effect Estimations. Every regression controls for time dummies. Dependent Variable is the Interquartile Range, D2575, or Standard Deviation, STD, for Total Factor Productivity Index, TFP, and Labour Productivity, LP

rests on the fact that less productive domestic firms, competing mostly on price, may be crowded out by the growing inflow of cheap foreign goods originating from LMCs. Their rivals in developing countries can benefit from lower labour and material costs and may, then, represent a serious threat for their survival. Additionally, domestic firms at the lower tail of the productivity distribution may have more incentives, with respect to other firms, to increase their efficiency since they are the main candidates to exit the market following the increased competitive pressures of LMCs (Muendler 2004). As a consequence, the dispersion decreases because of both the exit of low efficient firms and the productivity improvements of surviving firms.

On the contrary, domestic firms are used to face imports from advanced countries that have been quite constant over the sample period if compared with imports from other origins. Hence, firms may not be displaced by this competition. Also, since these flows of goods are characterised by a superior technology they may have a discouraging effect on domestic firms (Aghion and Griffith 2005) and only firms close to the productive frontier may engage in innovative efforts in order to gain in productivity and prevent the entry of potential foreign competitors (Aghion et al. 2005; Iacovone 2009). Therefore, a different mechanism could be at work. Openness to trade with developed countries offers the opportunity to exploit higher quality and higher technology intermediates that allow firms to increase their efficiency and competitiveness. Due to the high costs involved in the entry in foreign supply markets (Vogel and Wagner 2010) only the most productive firms may reap these benefits leading to an exacerbation of the within-sector productivity disparities between firms 
exploiting foreign inputs and the ones only using the domestic ones. I will investigate in more detail the mechanisms behind the effects of import penetration in Section 5.

Concerning the remaining determinants, in contrast to expectations, the domestic competitive context captured by the concentration ratio, $C 10$, does not have any significant effect on sectoral dispersion. Capital intensity contributes instead to shape sectoral productivity distribution. A high capital/labour ratio, $K L$, could reveal high entry barriers that reduce the competitive pressure in the sector by potential entrants and allow the survival of low efficient established firms. For the other two explanatory variables, $L E V$ and $R D$, I find different results making use of the two dispersion indicators. Interquartile range is negatively and significantly affected by the firm access to debt capital in the sector/area and by the sectoral R\&D intensity. The availability of external financial resources may allow firms-especially small firms facing a lack of internal resources - to invest in order to improve their efficiency and, as a consequence, it may reduce the productivity differences among firms caused by different internal financial conditions. $R \& D$ expenses also lower the interquartile range. Innovation increases competitiveness in the sector and firms that are not able to engage in $R \& D$ activity can not survive in the market. Additionally, domestic technology may be relatively cheaper if compared with the foreign technology embodied in goods imported from developed countries, and also low productive firms may take advantage from domestic new technologies in order to improve their efficiency. My findings suggest that, while the access to foreign technology is confined to a part of firms' population, the domestic technology seems to be accessible to all firms. Finally, knowledge spillovers stemming from the spread of technologies could help to remove the disparities across firms. However, it is worth to notice that in the estimations for the standard deviation the latter factors, debt share and R\&D, even preserving the negative sign, are not significant.

\subsection{Robustness checks}

I test the robustness of the previous findings to different measures of the dependent variable. First, I estimate total factor productivity by means of the Levinshon and Petrin (2003), TFP ${ }^{\mathrm{LP}}$, approach solving the simultaneity problem driven by the correlation between productivity and input choices. Then, I compute productivity following the criticism of Ackerberg et al. (2006), TFP ${ }^{\mathrm{ACF}}$, to the Levinshon and Petrin (2003) methodology, pointing at the bias and inconsistency in assuming labour as a flexible input in a real market where hiring/firing costs and search costs create an adjustment friction. Finally, I exploit the approach of Wooldridge (2009), TFP WO, proposing a one-step estimation of production function that is also robust to robust to the Ackerberg et al. (2006) critique. ${ }^{15}$ The first two columns of Table 3 display

\footnotetext{
${ }^{15} \mathrm{TFP}^{\mathrm{LP}}$ has been obtained making use of the Stata routine levpet, while $\mathrm{TFP}^{\mathrm{WO}}$ is obtained exploiting the command ivreg2. For TFP ${ }^{\mathrm{ACF}}$ estimations I developed my own routine. In all cases I estimate the production function separately for each 2-digit NACE sector and material costs are used as proxy for unobservable productivity shocks due to the lack of data about fuel, electricity and other energy costs.
} 


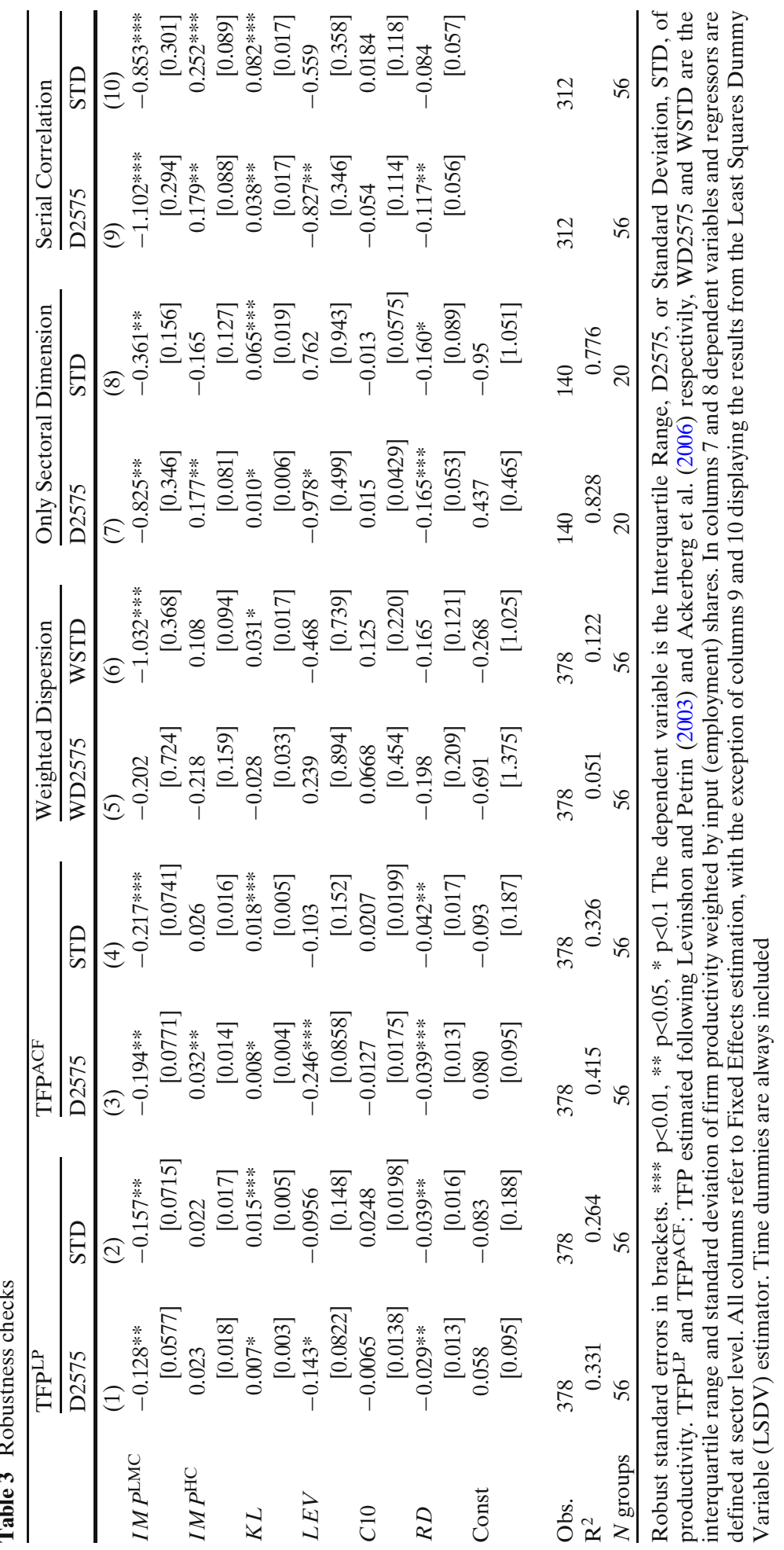


my findings when I use the dispersion indicators computed for TFP ${ }^{\mathrm{LP}}$ and TFP $\mathrm{ACF}$. In both cases dispersion is standardized by the sectoral median productivity in order to take into account the scale differences among industries (Syverson 2004). Results obtained exploiting TFP ${ }^{\mathrm{WO}}$ estimates deliver similar insights and are not shown for the sake of brevity, but are available from the author upon request. Summing up, main results are not affected by the change in the estimation methodology of TFP.

I also compute a dispersion indicator weighted by input shares. ${ }^{16}$ The latter has the advantage of being more linked to the between component of the sectoral productivity growth and of capturing the process of reallocation of resources across firms. However, it has the disadvantage of neglecting the role of smaller and marginal firms that may be the ones more exposed to the foreign competition. WD2575 and WSTD are the weighted interquartile range and the weighted standard deviation, respectively. The resulting findings, presented in columns 5-6, confirm the role of import penetration from low income countries when I focus on standard deviation, on the contrary no significant impact is detected for the inflows of goods originating from developed countries. Also, for interquartile range no relevant effect is disclosed for imports, even if the coefficients preserve the previous signs. Indeed, if the focus is on the process of reallocation of resources the standard deviation indicator may better capture the dynamics within the whole sector, while the interquartile range captures the dynamics at the tails of the productivity distribution and may miss the changes occurring in the rest of firm population. Hence, I am not concerned about the lack of any significant effect in the estimates for WD2575.

In columns 7-8 the analysis is implemented on the 2-digit sector basis instead of the sector/area basis. Both dependent variable and explanatory regressors are defined at sector level as in the literature (Syverson 2004; Del Gatto et al. 2008; Ito and Lechevalier 2009). Neglecting the regional dimension does not change the previous findings and the import penetration ratios preserve the significance and sign shown in the Section 4: a positive sign for the flows from developed countries and a negative one for the flows from developing countries. However, as already mentioned, data corroborate the relevance of the geographical dimension since Table 8 in the Appendix discloses the existence of a significant variation of the dispersion measure across areas and within sectors. As a consequence, in the following I continue to use the sectoral and regional analysis. ${ }^{17}$

Up to now, I have not dealt with the problem of the potential first-order serial correlation in the dispersion indicators. Even if both the generalized least squares estimator (Beck and Katz 1995) and the generalized method of moments estimator allow to correct for the serial correlation they are not appropriate for the setting under analysis, since the cross-sectional dimension of the panel is small but it is large

\footnotetext{
${ }^{16}$ I used employment shares. Results are similar when I use output shares as weights and are available upon request.

${ }^{17}$ A criticism may concern the geographical breakdown. The region Sardinia, that is included in the South area, may induce some bias in the results since it is geographically distant from the rest of Italy. Hence, I tried to exclude this region from the computation of my dependent and explanatory variables. This analysis, confirming the previous evidence, is available upon request.
} 
relative to the time series dimension. For these reasons I apply the Least Squares Dummy Variable (LSDV) estimator with the correction suggested by Kiviet (1995, 1999) and extended to unbalanced panels with strictly exogenous variables by Bruno (2005). The last two columns of the Table show that the LSDV estimator performs better for interquartile range than for standard deviation. The lag of the dependent variable is indeed not significant in the standard deviation regression. However, my previous findings are confirmed and both the sign and significance of the coefficients are maintained.

\section{Assessing the channel: competition versus greater availability of intermediates}

In this section I explore which mechanisms drive the impact of trade openness on within-sector productivity heterogeneity, and I investigate whether the different effects on dispersion, I have previously hypothesized, related to the competitive pressure and to the increased availability of intermediates following the inflows of imported goods are indeed at work. A foreign intermediate good belonging to a broadly defined sector may both represent an input for downstream firms, operating in that broad sector but in a downstream sector defined at a finer disaggregation, and be in competition with the same type of good produced by domestic firms. However, a foreign final product is directly purchased by final consumers and imports of final goods may only capture and reveal the competition channel. Hence, I compute an indicator of import competition of final goods, split by origin country. In order to identify the imported final goods - total and by country source-of each 2 digit NACE sector, I retained the Harmonised System (HS) import flows representing flows of consumption goods according to Broad Economic Category (BEC) classification and matched them with NACE sectors by means of the HS/NACE correspondence table available in RAMON Eurostat. The BEC codes identifying consumption goods are the following: 112, 122, 522, 61, 62, 63, 7. The import flows at HS product level are retrieved from the COMTRADE-WITS database, and, as a consequence, imports of final goods may only be computed at sector level, since no information about the Italian geographical area of destination is available in this database. Columns 1-2 in Table 4 show that the final goods purchased from developed countries have no impact on the productivity dispersion, on the contrary a negative impact emerges for final goods originating from low income economies. These findings hold when I exploit the lag of the imports of final goods and the results are available upon request. The purchases of foreign final goods do not completely capture the competition from imports, since foreign intermediates, that are not included in this new indicator, may represent a substitute of other domestic intermediates. ${ }^{18}$ However, this analysis confirms that the flows of foreign goods,

\footnotetext{
${ }^{18}$ Only the availability of very disaggregated data for productivity and trade and disaggregated InputOutput Tables may allow to completely distinguish the channel of competition from the one linked to the intermediates availability.
} 
that directly compete with domestic goods in the final market, contribute to reduce the sectoral dispersion when they come from low income countries even if the competition effect may be underestimated.

On the other side, if the higher dispersion caused by trade flows from high income countries is due to the easier access to a large variety of inputs I would expect an indicator of international offshoring to be significant in explaining the heterogeneity in firm productivity. Making use of the National import-use IO Tables I compute a broad measure of offshoring at the 2 digit level including intermediates purchases from all sectors, $O F F$. Again, an indicator capturing also the geographical dimension is not available. From columns 3-4 of the Table 4 it emerges a positive impact of the larger availability of intermediates following the offshoring strategies on the dispersion. Therefore, since the largest amount of inputs comes from developed countries (Falk and Wolfmayr 2008) it is likely that the latter drive the above result. I then split the offshoring activity by origin country. IO tables do not contain any information about the country of the imported inputs and, as standard in the literature, I make use of the import share of each country groups retrieved from trade data. I use the intermediates import share by origin and I obtain the offshoring indicator to high income countries, $\mathrm{OFF}^{\mathrm{HC}}$, and to low income countries, $\mathrm{OFF}^{\mathrm{LMC}}{ }^{19}$ A positive impact of offshoring to high income countries on dispersion is confirmed.

All this evidence indeed reveals that, while the foreign competition of developing economies contributes to reduce the within-sector productivity heterogeneity, the access to foreign intermediates from high income countries, when significant, increases the dispersion. ${ }^{20}$

To shed further light on my findings I test for additional trade variables that may complement my previous analysis or capture other dimensions of international integration. First, in columns 7-8 I add the output tariffs computed, by means of COMTRADE-WITS dataset, as simple sectoral averages across HS products by 2digit sector, TARIFFS. Output tariffs should reveal the process of trade liberalization and the resulting increase in competition from foreign goods. This measure

\footnotetext{
${ }^{19}$ The shares of imported intermediates from a sector $i$ used in a sector $j$ are obtained from IO Tables. Intermediates import share by origin for each sector $j$ are instead retrieved from WITSCOMTRADE database. As for final goods, intermediate imports are defined making use of the BEC classification.

${ }^{20}$ The relevance of import penetration on shaping area-sectoral productivity distribution emerges from my analysis. However, the new international trade literature based on firm heterogeneity (Bernard et al. 2003) also predicts overall productivity improvements following increased import flows. I have, then, tested the same covariates used in the analysis of dispersion indicators as determinants of both the area-sectoral median and weighted average productivity. No significant impact of current import penetration ratios on average efficiency levels is detected. I find, instead, that the first lag of import penetration from low income countries has a positive effect on median productivity, while the second lag of foreign goods purchases from developed economies enhances both the median level and the weighted mean of productivity. This evidence reveals that even if import flows contribute to shape the sectoral productivity distribution, the induced process of reallocation of resources and firm exits may take some time to display its positive effects on overall efficiency. These results are available from the author upon request.
} 


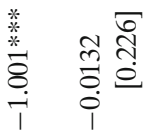

*

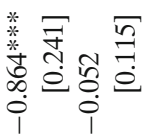

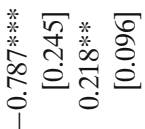

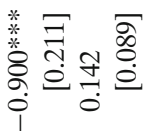

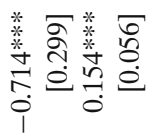

空 㐘

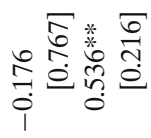

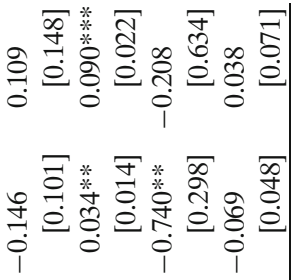

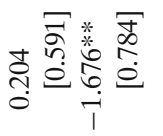

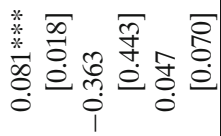

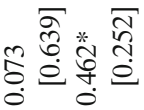

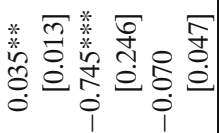

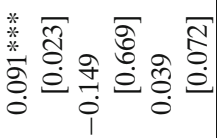

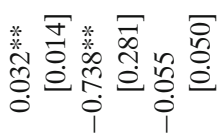

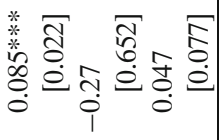

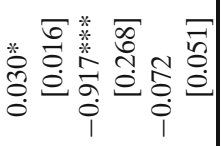

*

ô

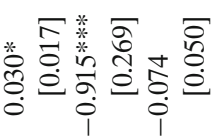

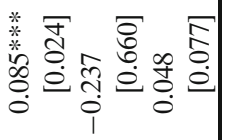

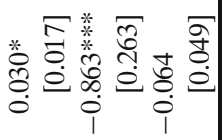

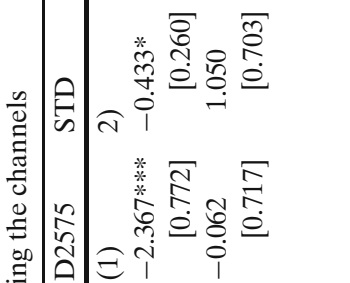

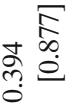

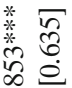

* $\overline{\widetilde{m}} \bar{\nabla}, \overline{\vec{\pi}}$

*

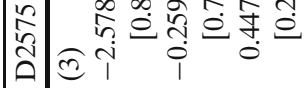

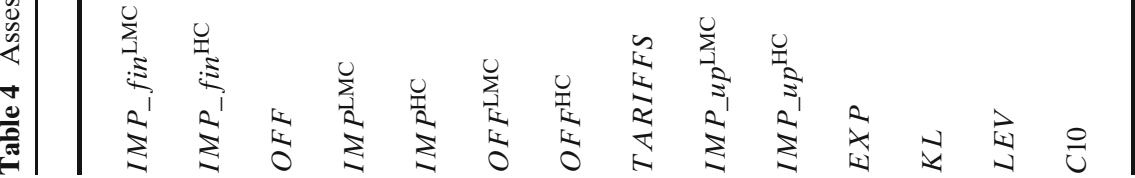




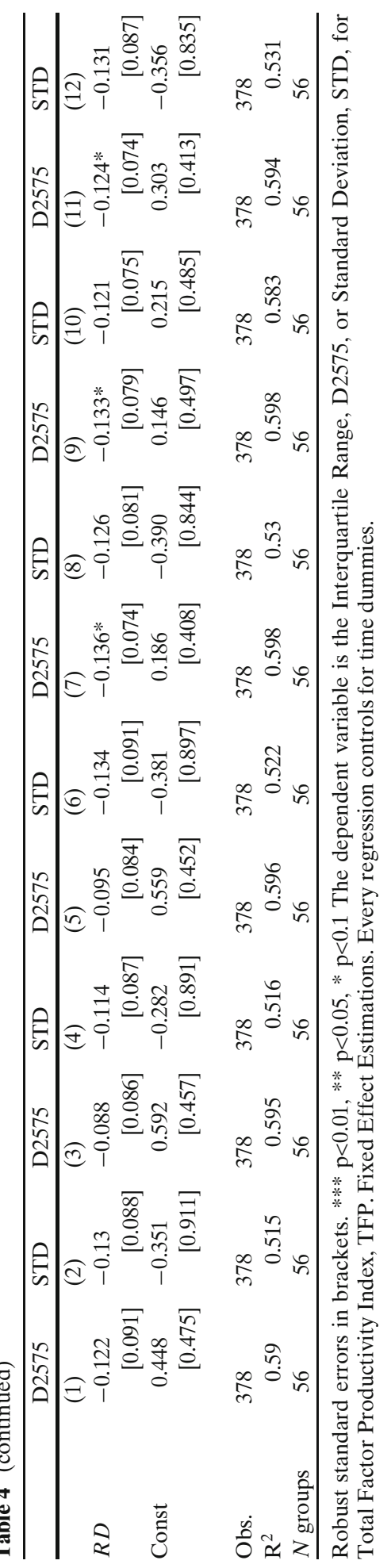


positively affects the sectoral interquartile range regardless of the inclusion in the estimation of the import penetration indicators. The results obtained when all measures of imports are excluded are not shown for the sake of brevity. However, this indicator may present the same problem detected for overall import penetration and potentially reflects both the effects related to the expanded access to intermediates and the effects of increased competition.

Second, I test for a measure of import penetration of upstream industries for each sector and area, built as the average of the import shares by origin country of upstream sectors weighted by the input shares of each supplier sector on total inputs. The resulting indicators, $I M P \_u p^{\mathrm{LMC}}$ and $I M P \_u p^{\mathrm{HC}}$, may help in capturing the larger availability of inputs originating from other sectors together with potential efficiency improvements experienced by supplier sectors due to their trade openness. Therefore, no robust effect is found out for these variables and offshoring indicators appear to better measure the expanded imported input variety (Columns 9-10). The main evidence on the other variables stay unchanged.

Finally, I check for the export openness of the industry/area, EXP, that may highlight the effect of the new opportunities of business delivered by the penetration in foreign markets. This indicator does not seem to play any role on sectoral productivity heterogeneity, thus confirming that the impact of trade openness works through increased competition and larger availability of intermediates instead of working through easier penetration of export markets. The same is true when I exclude from the regression the import penetration ratios because of the high correlation between the latter and export openness.

This investigation is robust when I restrict the analysis to the sectoral dimension, ${ }^{21}$ neglecting the geographical one and the relative results are available from the author upon request.

\section{Conclusions}

During the last decade Italy has experienced a rapid growth in import penetration, especially from low and medium income countries. This trend has been common to all developed countries and it is in great part attributable to the liberalization process of emerging countries and their industrial development. I analyse whether competition stemming from imports has contributed to shape the sectoral productivity distribution and firm dynamics. The existence of large and persistent differences in productivity levels among firms, even within narrowly defined sectors, is a stylised fact confirmed for different countries. Taking into account the importance of a

\footnotetext{
${ }^{21}$ Indeed, the following variables, imports of final goods from high and low income countries, offshoring measures split by country origin and tariffs, only vary by sector. Hence, a sectoral analysis is also required.
} 
geographical perspective for competition and productivity dynamics I construct dispersion indicators separately for each sector and geographical area. I show that, within a comprehensive framework, the exposure to LMCs is negatively related with the productivity dispersion at sector-area level. On the contrary, imports from high income countries contribute to widen within-sector heterogeneity. Two different channels drive these effects: imports from low wage economies have tightened up the competitive pressure and goods from developing countries are likely to directly compete with and crowd out less efficient firms. The role of flows from high income countries lies instead on the easier access for a part of firms' population to a larger variety of inputs. The within-sector disparities across firms are also significantly related to the presence of sunk costs, captured by capital intensity.

The analysis of the evolution of productivity distribution is an interesting topic ad may provide relevant insights about the growth process. Studies at sector level should pay more attention on productivity dispersion and firm level investigations should allow for heterogeneous firm responses to trade openness, technological factors and other external shocks. An average outcome can hide different dynamics at the firm level according to the firm position in the efficiency distribution. Consequently, the availability of longitudinal datasets covering the whole firm population, especially small firms, may be valuable in order to highlight the differences existing across firms and the evolution of these disparities over time. The use of larger samples would also offer the opportunity to focus on the dynamics within narrowly defined sectors and regions.

Finally, my analysis shows the importance of investigating in sector level studies which mechanisms drive the effects related to import penetration in order to discriminate between the expanded input variety and the competition channels.

Acknowledgements I wish to thank Giuliano Conti and Alessia Lo Turco for useful comments. An earlier and different version of this paper was presented at 2009 CAED (Comparative Analysis of Enterprise Data) Conference held in Tokyo. The usual disclaimers apply.

\section{Appendix}

Additional Tables

Table 5 Firm distribution across size classes

Source: own elaborations with AIDA dataset. The sample includes 20,394 firms in 1998 and 25,284 firms in 2004

\begin{tabular}{lcr}
\hline Size class & 1998 & 2004 \\
\hline$<20$ employees & 37.11 & 38.06 \\
20-49 employees & 36.03 & 36.54 \\
$50-249$ employees & 23.46 & 22.16 \\
$\geq 250$ employees & 3.41 & 3.25 \\
Total & 100.00 & 100.00 \\
\hline
\end{tabular}


Table 6 Cost shares used in the TFP index computation

\begin{tabular}{llll}
\cline { 2 - 4 } Table 6 Cost shares used in & NACE & K_sh & L_sh \\
\cline { 2 - 4 } the TFP index computation & Sector & 0.287 & 0.713 \\
& 15 & 0.179 & 0.821 \\
& 17 & 0.124 & 0.876 \\
& 19 & 0.125 & 0.875 \\
& 20 & 0.195 & 0.805 \\
& 21 & 0.221 & 0.779 \\
& 22 & 0.148 & 0.852 \\
& 24 & 0.200 & 0.800 \\
& 25 & 0.201 & 0.799 \\
& 26 & 0.227 & 0.773 \\
& 27 & 0.207 & 0.793 \\
& 28 & 0.153 & 0.847 \\
& 29 & 0.122 & 0.878 \\
& 30 & 0.097 & 0.903 \\
& 31 & 0.122 & 0.878 \\
K_sh and L_sh are the capital & 32 & 0.117 & 0.883 \\
cost shares and labour cost & 35 & 0.109 & 0.891 \\
shares, respectively & 36 & 0.160 & 0.840 \\
& 33 & 0.171 & 0.829 \\
& & 0.156 & 0.844 \\
\hline
\end{tabular}

Table 7 Distribution of observations across sectors and geographical areas

Period 1998-2004. For the definition of geographical areas see the footnote 3. - : excluded area-sector pairs because of the very low number of firm observations, or the lack of data about some covariates

\begin{tabular}{lrrr}
\hline NACE & \multicolumn{3}{l}{ Geographical Area } \\
\cline { 2 - 4 } Sector & North & Centre & South \\
\hline 15 & 6,762 & 1,955 & 2,016 \\
17 & 8,190 & 2,667 & 430 \\
18 & 3,081 & 1,189 & 608 \\
19 & 1,262 & 2,949 & 256 \\
20 & 2,954 & 614 & 308 \\
21 & 2,740 & 977 & 288 \\
22 & 5,202 & 1,382 & 398 \\
24 & 6,143 & 1,138 & 626 \\
25 & 8,049 & 1,088 & 760 \\
26 & 6,629 & 2,247 & 1,613 \\
27 & 3,587 & 465 & 311 \\
28 & 23,274 & 3,145 & 2,183 \\
29 & 21,789 & 2,530 & 891 \\
30 & 643 & 222 & - \\
31 & 6,704 & 1,142 & 493 \\
32 & 1,845 & 446 & - \\
33 & 3,607 & 451 & - \\
34 & 1,746 & 193 & - \\
35 & 793 & 321 & 651 \\
36 & 8,054 & 2,597 &
\end{tabular}


Table 8 TFP dispersion indicators at sector and area level

\begin{tabular}{lllr}
\hline & & D2575 & STD \\
\hline MEAN & & 0.579 & 0.605 \\
SD & All area/sector pairs & 0.130 & 0.127 \\
SD & Within-sector, across areas & 0.111 & 0.115 \\
SD & Within-area, across sectors & 0.123 & 0.122 \\
\hline
\end{tabular}

The table shows the mean (MEAN) and standard deviation (SD) of the productivity dispersion measures at area and sector level, that are D2575 and STD. Also, the average within-sector standard deviation of dispersion indicators across areas and the average within-area standard deviation across sectors are displayed. In order to compute the former (latter), I obtained the standard deviation of D2575 and STD indicators across areas (sectors) by sector (area) and, then, I averaged the resulting standard deviations over sectors (areas)

Table 9 Output distribution across 2-digit NACE sectors

\begin{tabular}{llrr}
\hline NACE & Description & 2004 & \\
\cline { 3 - 4 } & & Universe & Sample \\
\hline 15 & Food and beverages & 14.13 & 12.00 \\
17 & Textiles & 4.43 & 4.45 \\
18 & Wearing apparel & 3.84 & 2.80 \\
19 & Leather products and footwear & 2.91 & 1.95 \\
20 & Wood products & 2.29 & 1.34 \\
21 & Paper and paper products & 2.25 & 1.94 \\
22 & Printing and editing & 3.32 & 3.33 \\
24 & Chemical products & 8.70 & 10.05 \\
25 & Rubber and plastics & 4.44 & 5.22 \\
26 & Non metallic mineral products & 4.79 & 5.99 \\
27 & Basic metals & 5.70 & 5.34 \\
28 & Fabricated metal products & 10.41 & 10.06 \\
29 & Mechanical machineries & 12.54 & 13.28 \\
30 & Office machines and equipment & 0.51 & 0.25 \\
31 & Electrical machines and appliances & 3.85 & 5.01 \\
32 & Radio, TV and communication appliances & 1.66 & 2.50 \\
33 & Medical, optical and precision appliances & 1.87 & 1.40 \\
34 & Motor vehicles and transport equipment & 5.95 & 7.33 \\
35 & Other transport equipment & 1.97 & 1.74 \\
36 & Furniture and other manufacturing & 4.45 & 4.01 \\
& Total & 100.00 & 100.00 \\
\hline
\end{tabular}

Source: own elaborations with AIDA dataset and Firms' Economic Accounts

Table 10 Correlation ratios

\begin{tabular}{lcrrrrrr}
\hline & $I M P^{\mathrm{LMC}}$ & $I M P^{\mathrm{HC}}$ & $K L$ & $C 10$ & $L E V$ & $R D$ & $O F F$ \\
\hline$I M P^{\mathrm{LMC}}$ & 1 & & & & & & \\
$I M P^{\mathrm{HC}}$ & -0.003 & 1 & & & & & \\
$K L$ & $-0.180^{*}$ & $-0.217^{*}$ & 1 & & & & \\
$C 10$ & 0.064 & $0.487^{*}$ & $0.110^{+}$ & 1 & & & \\
$L E V$ & $0.155^{*}$ & $0.216^{*}$ & $-0.563^{*}$ & $-0.117^{+}$ & 1 & & \\
$R D$ & $-0.238^{*}$ & $0.265^{*}$ & $-0.258^{*}$ & -0.077 & $0.141^{*}$ & 1 & \\
$O F F$ & $0.103^{+}$ & $0.734^{*}$ & -0.071 & $0.460^{*}$ & 0.018 & $0.217^{*}$ & 1 \\
\hline
\end{tabular}

* Correlations are significant at $1 \% .{ }^{+}$Correlations are significant at $5 \%$ 


\section{References}

Ackerberg DA, Caves K, Frazer G (2006) Structural identification of production functions. UCLA Economics Department

Aghion P, Griffith R (2005) Competition and growth: reconciling theory and evidence. MIT Press, Cambridge and London

Aghion P, Burgess R, Redding S, Zilibotti F (2005) Entry liberalization and inequality in industrial performance. J Eur Econ Assoc 3(2-3):291-302

Altomonte C, Barattieri A, Rungi A (2008) Import penetration, intermediate inputs and productivity: evidence from Italian firms. Working paper, Bocconi University, Milan

Amiti M, Konings J (2007) Trade liberalization, intermediate inputs, and productivity: evidence from Indonesia. Am Econ Rev 97(5):1611-1638

Bartelsman EJ, Doms ME (2000) Understanding productivity: lessons from longitudinal microdata. J Econ Lit 38(3):569-594

Becchetti L, Trovato G (2002) The determinants of growth for small and medium sized firms. The role of the availability of external finance. Small Business Econ 19:291-306

Beck N, Katz JN (1995) What to do (and not to do) with time-series cross-section data. Am Polit Sci Rev 89:634-647

Bekes G, Kleinert J, Toubal F (2009) Spillovers from multinationals to heterogeneous domestic firms: evidence from Hungary. World Econ 32(10):1408-1433

Bernard AB, Eaton J, Jensen JB, Kortum S (2003) Plants and productivity in international trade. Am Econ Rev 93:1268-1291

Bruno G (2005) Approximating the bias of the LSDV estimator for dynamic unbalanced panel data models. Econ Lett 87:361-366

Bugamelli M, Rosolia A (2006) Productivity and foreign competition. Bank of Italy Economic Research Paper N. 578

Caves DW, Christensen LR, Diewert WE (1982) Comparisons of output, input, and productivity using superlative index numbers. Econ J 92(365):73-86

Daveri F, Jona-Lasinio C (2005) Italy's decline: getting the facts right. giornale degli economisti. Giornale degli Economisti e Annali di Economia 64(4):365-410

Del Gatto M, Ottaviano GI, Pagnini M (2008) Openness to trade and industry cost dispersion: evidence from a panel of italian firms. J Regional Sci 48(1):97-129

Dimova R (2008) The impact of labour reallocation and competitive pressure on TFP growth: firmlevel evidence from crisis and transition ridden Bulgaria. Int Rev Appl Econ 22(3):321-338

Escribano AS Stucchi R (2008) Catching up in total factor productivity through the business cycle: evidence from Spanish manufacturing surveys. Economics working papers 085125, Universidad Carlos III

Falk M, Wolfmayr Y (2008) Services and materials outsourcing to low-wage countries and employment: empirical evidence from EU countries. Struct Change Econ Dyn 19:38-52

Fernandes AM (2007) Trade policy, trade volumes and plant-level productivity in colombian manufacturing industries. J Int Econ 71(1):52-71

Gatti R, Love I (2008) Does access to credit improve productivity? Econ Trans 16(3):445-465

Griffith R, Redding S, Simpson H (2003) Productivity convergence and foreign ownership at the establishment level. CEP Discussion Papers 0573, Centre for Economic Performance

Haller S (2008) The distribution of productivity in irish manufacturing between 1995 and 2004 determinants, changes and implications. Econ Soc Rev, Econ Soc Studies 39(1):13-38

Halpern L, Koren M, Szeidl A (2005) Imports and productivity. CEPR discussion papers 5139

Iacovone L (2009) The better you are the stronger it makes you: evidence on the asymmetric impact of liberalization. Policy research working paper series 4930, The World Bank

Ito K, Lechevalier S (2009) The evolution of the productivity dispersion of firms: a reevaluation of its determinants in the case of Japan. Rev World Econ 145(3):405-429

Jovanovic B (1982) Selection and the evolution of industry. Econometrica 50(3):649-670

Jovanovic B, Lach S (1997) Product innovation and the business cycle. Int Econ Rev 38:3-22

Kasahara H, Rodrigue J (2008) Does the use of imported intermediates increase productivity? Plantlevel evidence. J Dev Econ 87(1):106-118

Kiviet JF (1995) On bias, inconsistency and efficiency of various estimators in dynamic panel data models. J Econ 68:53-78

Kiviet JF (1999) Expectation of expansions for estimators in a dynamic panel data model; some results for weakly exogenous regressors. In: Hsiao C, Lahiri K, Lee LF, Pesaran MH (eds) Analysis of panel data and limited dependent variables. Cambridge University Press, Cambridge 
Kremp E, Mairesse J (1991) Dispersion and heterogeneity of firm performances in nine french service industries, 1984-1987. NBER working papers 3665, National Bureau of Economic Research

Levinsohn J, Petrin A (2003) Estimating production functions using inputs to control for unobservables. Rev Econ Stud 70:317-341

Melitz MJ (2003) The impact of trade on intra-industry reallocations and aggregate industry productivity. Econometrica 71(6):1695-1725

Muendler MA (2004) Trade, technology, and productivity: a study of brazilian manufacturers, 19861998. Economics working paper series 2004-006, University of California at San Diego

Nunes PM, Sequeira TN, Serrasqueiro Z (2007) Firms' leverage and labor productivity: a quantile approach in portuguese firms. Appl Econ 39:1783-1788

Ottaviano GIP, Puga D (1998) Agglomeration in the global economy: a survey of the 'new economic geography'. World Econ 21(6):707-731

Oulton N (1998) Competition and the dispersion of labour productivity amongst UK companies. Oxf Econ Pap 50(1):23-38

Pavcnik N (2002) Trade liberalization, exit, and productivity improvement: evidence from chilean plants. Rev Econ Stud 69(1):245-276

Rodrik D (1991) Closing the technology gap: does trade liberlaization really help? NBER working papers 2654, National Bureau of Economic Research

Sabirianova KP, Svejnar J, Terrel K (2005) Distance to the efficiency frontier and foreign direct investment spillovers. J Eur Econ Assoc 3(2):576-586

Schor A (2004) Heterogeneous productivity response to tariff reduction: evidence from brazilian manufacturing firms. J Dev Econ 75(2):373-396

Syverson C (2004) Product substitutability and productivity dispersion. Rev Econ Stat 86(2):534-550

Khandelwal A, Topalova P (2011) Trade liberalisation and firm productivity: the case of India. Rev Econ Stat 93(3):995-1009

Van Biesebroeck J (2007) Robustness of productivity estimates. J Indust Econ 55(3):529-569

Vogel A, Wagner J (2010) Higher productivity in importing german manufacturing firms: selfselection, learning from importing, or both? Rev World Econ 145(4):641-665

Wooldridge JM (2002) Econometric analysis of cross section and panel data. MIT Press, Cambridge

Wooldridge JM (2009)On estimating firm-level production functions using proxy variables to control for unobservables. Econ Lett 104(3):112-114 